\title{
Optimization of Burning Production Process of Ceramsite with Specified Density
}

\author{
Galitskov K.S., Samokhvalov O.V., Fadeev A.S. \\ Samara State Technical University, Institute of Architecture and Civil Engineering \\ Address: Molodogvardeyskaya St., 194, Samara, 443001, Russia
}

\begin{abstract}
The paper goes into peculiarities of using developed mathematical models of ceramsite burning and computational models created on their basis. The work is done in the light of analysis and synthesis of multivariate control system of kiln angular velocity and kiln charge with volumetric thermal capacity burners. It is shown that computational models of burning as an object of control are problem-oriented on producing ceramsite with specified density. Mathematical model of ceramsite burning process as an object with distributed parameters is synthesized. The transition from model with distributed parameters to the mode with lumped parameters is performed. Then the authors used a model with three bearing cross-sections along Z-axis in Matlab software and created a computational model of multivariate object of control with inter-channel connections. The paper presents experimental computational set up methods and methods of ceramsite burning optimal curve identification on the criterion of minimizing energy consumption for burning. The developed method of staging computational experiments makes it possible to predict the strength of ceramsite if values of control actions are known. The results of modeling help create methodology of choosing optimal modes of ceramsite burning with the required mark of strength and with minimum energy consumption.
\end{abstract}

Keywords: claydite, rotary kiln, strength and bulk density of ceramsite, mathematical model.

\section{INTRODUCTION}

Ceramsite production is in itself a sequential execution of technological processes, among which the most significant process is that of burning. It is usually performed in a rotary drum kiln, with the length (L) of $40 \mathrm{~m} \mathrm{[1].} \mathrm{In} \mathrm{the} \mathrm{kiln,} \mathrm{raw} \mathrm{clay} \mathrm{moving}$ from the download zone to the zone of unloading final product undergoes multiple technological transitions: drying, heating, swelling, and, finally, cooling [2]. Strength and density of ceramsite is determined mainly by two factors: physical-chemical characteristics of the original clay raw materials and a burning curve, which shows the dependence of ceramsite temperature changes $\mathrm{T}$ from its position along the axis of the kiln $\mathrm{T}(\mathrm{z})$, where $\mathrm{z} \in 0, \ldots$, L. In existing structures of kilns a burning curve is formed by a specialist (called "a burner") who implements heuristic algorithms of thermal power control of the burner $\mathrm{Q}_{\mathrm{b}}$, loading of the kiln $\mathrm{q}_{\mathrm{L}}$ and, less frequently, of angular velocity of the kiln $\omega_{\mathrm{k}}$. In some installations, used to control a burning curve, doubledrum kilns with drums rotating with different speeds are applied $[1,2]$.

Most famous publications, devoted to ceramsite production, describe technological issues covering the evaluation of clay characteristics [3-6], their influence on swelling, bulk density and ceramsite strength [7-10] and experimental research of burning curves and the like [11-14].

Ceramsite burning is a complex, energy-consuming process which is difficult to formalize. Therefore, experimental determination of desired modes of kiln operation, providing production of ceramsite with specified strength in conditions of minimal energy consumption while using existing technological equipment, requires a lot of time and money, and does not always produce optimal results. Under current conditions it is reasonable to solve this important production task by using mathematical modeling.

This paper is a further step in research previously carried out by the authors and aimed at automation of technological-processes of ceramsite burning. This work describes the basic stages for solving tasks of automatic control of burning by using mathematical models. It also demonstrates different ways of finding optimal decisions with important practical application at each of these stages.

\section{DYNAMICS MODEL OF CERAMSITE BURNING IN ROTARY KILN}

Papers [15, 16] within known assumptions and simplifications introduce a physical model of the kiln as a rotating multilayer cylinder of Length $\mathrm{L}$ (see Figure 1). This cylinder consists of a steel jacket (1), fireclay bricks (2), ceramsite raw material (3), flue gases (4) of D1-D4 diameters, respectively. Raw ceramsite granules move along Axis $\mathrm{z}$ of the cylinder from a charging door to a transporting out zone at $v^{\mathrm{m}}$ speed. Gas-fired burner (5) creates flue gases moving with speed $v^{\text {fg }}$ toward the material. This process results in ceramsite burning. In this case, 
thermodynamics of flue gases can be described by a system of equations:

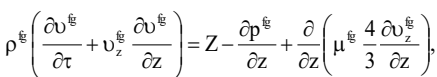

$\frac{\partial p^{\mathfrak{E}}}{\partial \tau}+\frac{\partial\left(\rho^{\mathbb{E}} v_{z}^{\mathfrak{E}}\right)}{\partial z}=0$

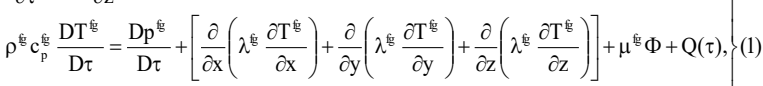

$\mathrm{p}^{\mathrm{f}}-\rho^{\mathrm{E}} \mathrm{RT} \mathrm{T}^{\mathfrak{E}}=0$,

$\mu^{\mathfrak{G}}=\mu_{0}{ }^{\mathfrak{f}}\left(T^{\mathfrak{E}}\right)$,

and dynamics of heat transfer in a solid body, in particular between the layers of rotary kiln and ceramsite, by the following equations:

$$
\left.\begin{array}{l}
\frac{\partial \mathrm{T}_{\mathrm{w}}(\mathrm{z}, \mathrm{r}, \tau)}{\partial \tau}=\mathrm{a}_{\mathrm{w}}(\mathrm{z})\left(\frac{\partial^{2} \mathrm{~T}_{\mathrm{w}}(\mathrm{z}, \mathrm{r}, \tau)}{\partial \mathrm{r}^{2}}+\frac{1}{\mathrm{r}} \frac{\partial \mathrm{T}_{\mathrm{w}}(\mathrm{z}, \mathrm{r}, \tau)}{\partial \mathrm{r}}+\frac{\partial^{2} \mathrm{~T}_{\mathrm{w}}(\mathrm{z}, \mathrm{r}, \tau)}{\partial \mathrm{z}^{2}}\right)-\mathrm{U}_{\mathrm{w}} \frac{\partial \mathrm{T}_{\mathrm{w}}(\mathrm{z}, \mathrm{r}, \tau)}{\partial \mathrm{z}}, \\
\frac{\partial \mathrm{T}_{\mathrm{f}}(\mathrm{z}, \mathrm{r}, \tau)}{\partial \tau}=\mathrm{a}_{\mathrm{f}}\left(\frac{\partial^{2} \mathrm{~T}_{\mathrm{f}}(\mathrm{z}, \mathrm{r}, \tau)}{\partial \mathrm{r}^{2}}+\frac{1}{\mathrm{r}} \frac{\partial \mathrm{T}_{\mathrm{f}}(\mathrm{z}, \mathrm{r}, \tau)}{\partial \mathrm{r}}+\frac{\partial^{2} \mathrm{~T}_{\mathrm{f}}(\mathrm{z}, \mathrm{r}, \tau)}{\partial \mathrm{z}^{2}}\right), \\
\frac{\partial \mathrm{T}_{\mathrm{w}}(\mathrm{z}, \mathrm{r}, \tau)}{\partial \tau}=\mathrm{a}_{\mathrm{w}}\left(\frac{\partial^{2} \mathrm{~T}_{\mathrm{w}}(\mathrm{z}, \mathrm{r}, \tau)}{\partial \mathrm{r}^{2}}+\frac{1}{\mathrm{r}} \frac{\partial \mathrm{T}_{\mathrm{w}}(\mathrm{z}, \mathrm{r}, \tau)}{\partial \mathrm{r}}+\frac{\partial^{2} \mathrm{~T}_{\mathrm{w}}(\mathrm{z}, \mathrm{r}, \tau)}{\partial \mathrm{z}^{2}}\right) .
\end{array}\right\}
$$

Here, $\quad v^{\mathrm{fg}}, \mathrm{p}^{\mathrm{fg}}, \rho^{\mathrm{fg}}, \mathrm{T}^{\mathrm{fg}}, \lambda^{\mathrm{fg}}, \mathrm{c}_{\mathrm{p}}^{\mathrm{fg}}, \mu^{\mathrm{fg}}$ are respectively velocity, pressure, density, thermal conductivity coefficient, temperature, specific thermal capacity (at constant pressure) and viscosity coefficient of flue gases; $X, Y, Z$ are force media projection of flue gases, related to the unit of volume; $\tau$ - time; $\quad \mathrm{D} v^{\text {fig }} / \mathrm{D} \tau, \mathrm{Dp}^{\text {fig }} / \mathrm{D} \tau, \mathrm{DT}^{\text {fig }} / \mathrm{D} \tau-$ substantial derivative of velocity, temperature and pressure; $\Phi$ is dissipative function (dissipation), $T_{M}, a_{M}, v_{M}-$ temperature, heat transfer coefficient and material velocity, respectively; $\mathrm{T}_{\mathrm{f}}, \mathrm{a}_{\mathrm{f}} ; \mathrm{T}_{\mathrm{w}}, \mathrm{a}_{\mathrm{w}}-$ temperature and heat transfer coefficient of the lining of shells and steel walls of the kiln, respectively.

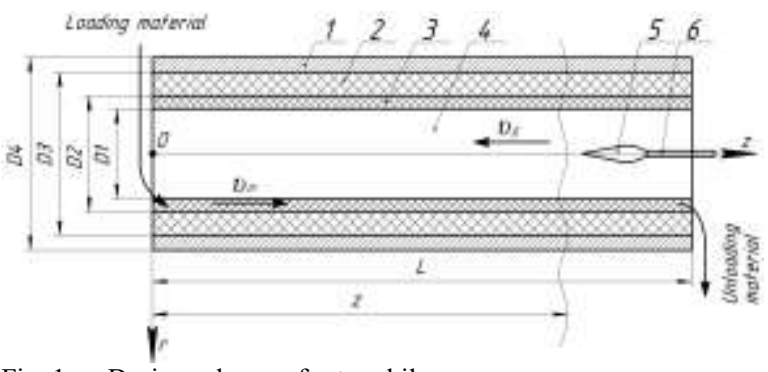

Fig. 1. Design scheme of rotary kiln

The solution of equations (1) and (2), supplemented by boundary conditions $[15,16]$ was carried out by a numerical method in SolidWorks computer software. A rotary kiln with $40 \times 2.5 \mathrm{~m}$ dimensions, equipped with a gas burner C199-08-100 was taken by way of example. Creating a computer model of the kiln in SolidWorks computer software includes the following steps: a) heat transfer: heat transfer in solid bodies, radiative heat transfer, volumetric heat source (simulating the torch of the kiln) with temperature of $1200^{\circ} \mathrm{C}$, rotation of the kiln; b) the composition of flue gases: $\mathrm{CO}_{2}-$ carbon dioxide, $\mathrm{N}_{2}$ - nitrogen, $\mathrm{O}_{2}$ - oxygen, $\mathrm{Ar}$ - argon, $\mathrm{H}_{2} \mathrm{O}$ - water vapor; c) type of gas flow - laminar; g) material of kiln layers: framework - steel St.3, lining - refractory brick, material being burnt - raw ceramsite; d) initial conditions of gas environment: temperature $-20^{\circ} \mathrm{C}$, speed $-30 \mathrm{~m} / \mathrm{s}$, e) initial and boundary conditions of the kiln; $\mathrm{k}$ ) parameters of computational grid. The researchers worked with two types of raw materials: the first was from easily swelling clay from Smyshlyaevka, the second was from iron clay with little swelling properties $[15,16]$.

The developed computational model makes it possible to perform two phases of testing the kiln. The main objective of the first phase is to assess the adequacy of models and optimization of coordinates choice of the kiln bearing cross-sections. Firstly, modeling of dynamics of kiln preheating in conditions of its rotating at a constant angular velocity is done. In this case, we should specify time (for example, 24 hours) of expected time interval necessary for the kiln to achieve steady temperature. As a result of these calculations, we found static temperature distribution of flue gases along the length of the rotary kiln. Comparison of the results obtained with empirical data makes it possible to evaluate the adequacy of the model in this technological mode.

Then we explored burning curves of ceramsite. In the calculation model, the adequacy of which was confirmed by the previous experiment, we specify the following parameters of raw material: moisture, density, thermal conductivity. For example, computational experiments to evaluate the impact of speed $\omega_{\mathrm{k}}$ on the strength $\mathrm{R}$ were performed with $3-\mathrm{x}$ values $\omega_{\mathrm{k}}=0.26 ; 0.13 ; 0.08 \mathrm{~s}^{-1}$. Comparison of burning curves, obtained in computational experiments [17], with the results obtained on the existing kiln, demonstrated that they differed by no more than 5\%, which confirms the adequacy of designed mathematical model.

The analysis of the multitude of burning curves allows to solve the first task of optimization - choice of coordinates for three bearing cross-sections $\mathrm{F}$, A and $\mathrm{C}$ along the length of the kiln [18]. It makes possible to justified the following three control actions: angular velocity of the kiln and its load, thermal power of the burner. In the second phase, we investigated dynamics of the burning process as a multivariate control object with distributed parameters, in which the temperature of ceramsite is controlled in three selected cross-sections.

The main objective of this phase is to justify the possibility of transition from kiln model as an object with distributed parameters to its model as a multivariate object of control with lumped parameters. 


\section{DYNAMICS MODEL OF CERAMSITE BURNING IN ROTARY KILN AS A MULTIVARIATE CONTROL OBJECT}

The second phase of the tests represents, in fact, identification of the kiln transfer function and transfer functions of the links of ceramsite burning process as multidimensional (especially 3D) object of control (see Figure 2) in its relation to both the vector $\bar{U}=$ $\left[\Delta \omega_{\mathrm{k}}, \Delta \mathrm{q}_{\mathrm{L}}, \Delta \mathrm{Q}_{\mathrm{b}}\right]^{\mathrm{T}}$ of control actions, and to the vector $\overline{\mathrm{H}}=\left[\Delta \mathrm{w}, \mathrm{T}_{\mathrm{e}}\right]$ of disturbances.

Here $\mathrm{T}$ is the vector of the output coordinates $\overline{\mathrm{T}}=$ $\left[\mathrm{T}_{\mathrm{F}}, \mathrm{T}_{\mathrm{A}}, \mathrm{T}_{\mathrm{C}}\right]$, where $\mathrm{T}_{\mathrm{F}}, \mathrm{T}_{\mathrm{A}}, \mathrm{T}_{\mathrm{C}}$ - the temperature of clay in selected sections of the kiln. The object structure is supplemented by the developed operator $\mathrm{S}_{1}$ through which the projected strength $\mathrm{R}$ and bulk density of ceramsite $\rho$, which is baked from clay with generalized characteristic of $\gamma$, raw material is characterized with moisture $\mathrm{w}$ and the burning curve is represented by the vector $\overline{\mathrm{T}}$.

To solve the described tasks by using our model (which adequacy was estimated in the first stage of the tests) the following experiments were performed:

1) Research of response functions (curves of the transition process) of ceramsite temperature in crosssections $\mathrm{F}, \mathrm{A}$ and $\mathrm{C}$ of the kiln to the step change "in the small" of one of the vector elements of control actions at constant values for the remaining elements of this vector and disturbances. Identification of separate links and inter-channel links of a multivariate object with respect to control in the form of dynamic models with lumped parameters.

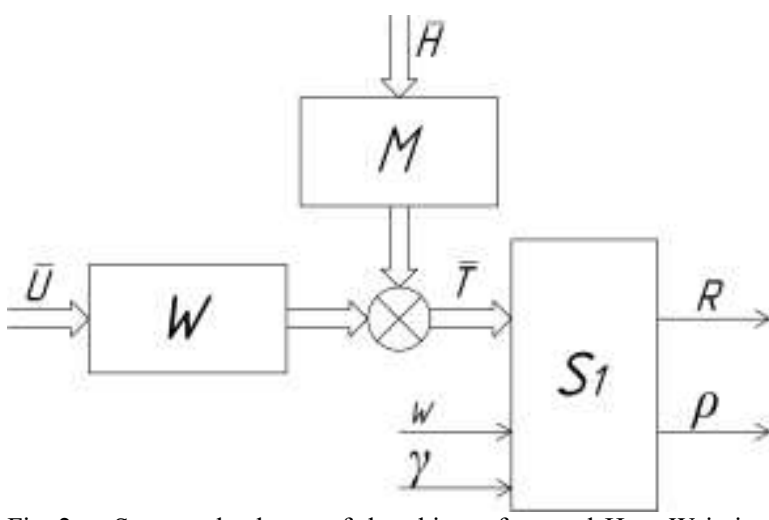

Fig. 2. Structural scheme of the object of control Here $\mathrm{W}$ is its own transfer functions, $\mathrm{M}$ is transfer functions of links for control, $\mathrm{H}$ is transfer functions in relation to disturbance.

2) Research of response functions (curves of the transition process) of ceramsite temperature in crosssections F, A and C of the kiln to the step change "in the small" of one of the disturbance areas (raw material moisture $\mathrm{w}$, external environment temperature $T_{c}$ ) at constant values for the remaining control effects and disturbances. Identification of separate channels and inter-channel links of a multivariate object with respect to disturbance in the form of dynamic models with lumped parameters.
3) Forecasting of strength $R$ and bulk density of ceramsite $\rho$ by using a computational model created in Matlab software and based on synthesized structure of multidimensional object of control (see Figure 2).

\section{OPTIMIZATION METHODOLOGY OF} CONTROL OF CERAMSITE BURNING PROCESS

Based on the developed model of the dynamics of the control object we synthesized a structure (see Figure 3) and created a computational model of multidimensional system of control of burning process in Matlab software.

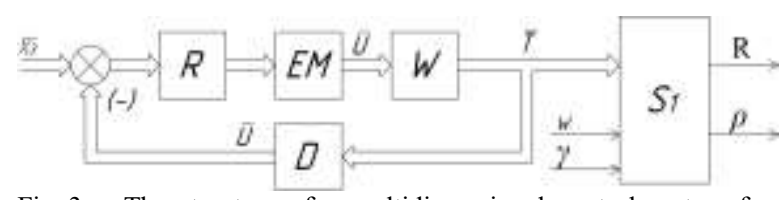

Fig. 3. The structure of a multidimensional control system for ceramsite burning: $\mathrm{EM}$ - an electromechanical part; $\overline{\mathrm{X}_{\mathrm{s}}}$ - a vector specifying exposure; D - a temperature sensor

The practical application of this model makes it possible, firstly, to perform parametric synthesis of regulators $\mathrm{R}$ of separate channels of multidimensional systems in conditions of inter-channels links and, secondly, to solve the problem of determining optimal control of ceramsite burning with account of achieving the required strength values in conditions of the least possible value of consumed energy [1921].

The use of Operator $S_{1}$ makes it possible to calculate permitted deviation values of elements $\overline{\mathrm{T}}$. These values still make possible to burn ceramsite of certain brands. As a result, in the space $\mathrm{OT}_{\mathrm{F}} \mathrm{T}_{\mathrm{A}} \mathrm{T}_{\mathrm{C}}$ we built a set of parallelepiped (see Figure 4) $\Pi_{i}$ $(i \in 1, \ldots, n$, where $n$ is the number of possible standard ceramsite grades according to its strength which can be produced by the oven). Here Volume $\mathrm{K}_{\mathrm{i}} \mathrm{L}_{\mathrm{i}} \mathrm{M}_{\mathrm{i}} \mathrm{N}_{\mathrm{i}} \mathrm{K}_{\mathrm{i}}^{\prime} \mathrm{L}_{\mathrm{i}}^{\prime} \mathrm{M}_{\mathrm{i}}^{\prime} \mathrm{N}_{\mathrm{i}}^{\prime}$ includes countless combinations of values of Vector $T_{i}=\left[T_{F i}, T_{A i}, T_{C i}\right]^{T}$, specifying temperatures which makes it possible to produce ceramsite of $\Pi_{i}$ grade.

When a working point (that is, a spherical solid) of a system of automatic control of ceramsite burning is inside one of these parallelepipeds, ceramsite of the brand corresponding to this volume will be produced.

It lies in the following assumption. Suppose we know the desired value of ceramsite brand $\mathrm{P}$ strength and the properties of raw materials loaded into the kiln, as well as its humidity. We have to find the optimum value of a vector element $\overline{\mathrm{T}}$ in which burning will be performed at the lowest achievable energy consumption. In conditions, when for each brand $\mathrm{P}$ in accordance with All Union State Standard (GOST) there exists some fairly significant in magnitude variation of strength $\mathrm{R}$, the unique solution of the task is impossible. Using the operator $S_{1}$ makes 
it possible to calculate permitted deviation values of elements $\overline{\mathrm{T}}$. These values still make possible to burn ceramsite of certain brands. As a result, in the space $\mathrm{OT}_{\mathrm{F}} \mathrm{T}_{\mathrm{A}} \mathrm{T}_{\mathrm{C}}$ a family of boxes (parallelepipeds) was built (see Figure 4).

When a working point of a system of automatic control of ceramsite burning is inside one of these parallelepipeds, ceramsite of the brand corresponding to this volume will be produced.

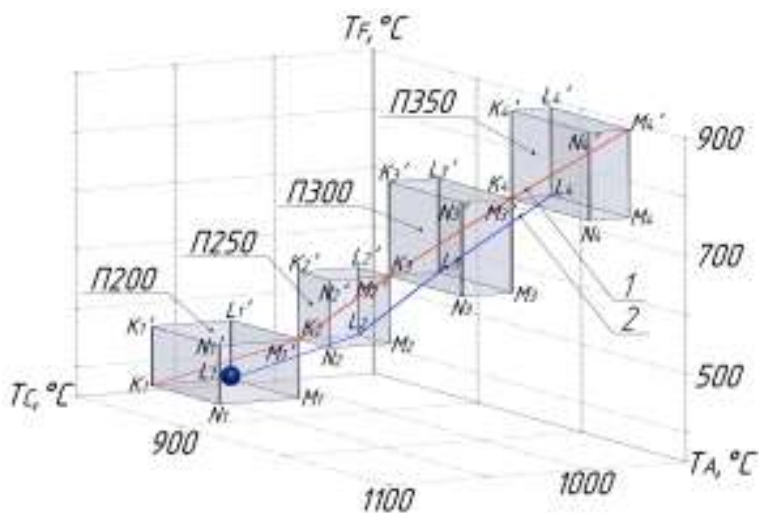

Fig. 4. The brand of ceramsite according to its strength in space $\mathrm{O}_{\mathrm{F}} \mathrm{T}_{\mathrm{A}} \mathrm{T}_{\mathrm{C}}, 1-\mathrm{a}$ polygonal curve of maximum strength, 2 - an energy efficient polygonal curve

We believe that the synthesized system allows to provide ceramsite temperature stabilization in three selected sections of the kiln to the specified accuracy. Figure 3 shows that the research on the model proved that production of ceramsite with specified strength will have the lowest energy consumption, if the working point of the automatic control system is in point (L) (shown in Figure 5) of the parallelepiped in question.

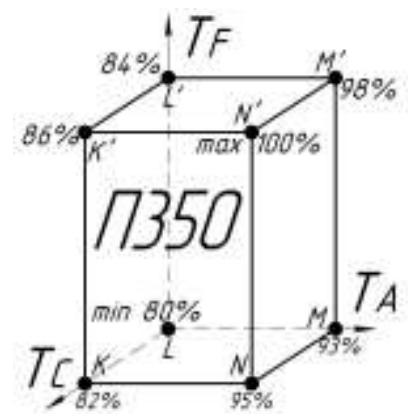

Fig. 5. Relative costs of gas (\%) for burning $1 \mathrm{~m}^{3}$ of ceramsite $\mathrm{P}$ 350 Brand in relation to the boundary points of the multidimensional phase space of the developed system of automatic control of ceramsite burning

\section{V.RESULTS AND DISCUSSION}

The research and its results show that the proposed approach to solving the problem of ceramsite with specified strength production in conditions of the minimum achievable energy consumption by applying the developed mathematical models of the kiln as an object of control, models of synthesized automatic control system of the burning process and the use of these models allows to use them while solving practical tasks to optimize the process of ceramsite burning.

The obtained results of solving this multi-criteria task of optimization also include the assessment of the adequacy of mathematical model of ceramsite burning as an object with distributed parameters, selection of bearing cross-sections coordinates of the kiln along its central axis, justification for the move from models with distributed parameters to the model with lumped parameters, selection of the optimal position (on the criterion of minimizing energy consumption for burning) of the working point of the system of automatic control in the limited space $\mathrm{OT}_{\mathrm{F}} \mathrm{T}_{\mathrm{A}} \mathrm{T}_{\mathrm{C}}$, corresponding to production of ceramsite with specified strength $\mathrm{P}$. The test results of research carried out on a specific example show that production of ceramsite with specified strength makes it possible to reduce energy consumption up to $20 \%$.

\section{CONCLUSION}

Theoretical aspects of optimization of ceramsite burning technological processes, described in the paper, are aimed to solve important practical tasks of automating production of ceramsite with specified strength (or density) by synthesis and implementation of multidimensional system control for the thermal field in the rotary kiln. Optimization of kiln operation was performed by using mathematical models of the burning process.

\section{REFERENCES}

[1] Lisienko V.G., Shchelokov Ya.M., Ladygichev M.G. Rotary kilns: heat engineering, management and ecology, Book 1, Moscow, Heating engineer, 2004, 688 p.

[2] Lisienko V.G., Shchelokov Ya.M., Ladygichev M.G. Rotary kilns: heat engineering, management and ecology, Book 2, Moscow, Heating engineer, 2004, 592 p.

[3] Yıldız M., Soğanci A.S. Effect of freezing and thawing on strength and permeability of lime-stabilized clays. Scientia Iranica, Vol. 19, Is. 4, 2012, pp. 1013-1017.

[4] Chuan Wang, n-Xin Chen, Chao Dang Yuan-Zhe Li, Aruna, Hai-Chao Li, Yu Huang Preparation of Ceramsite from C\&D Waste and Baiyunebo Tailings. Procedia Environmental Sciences, Vol. 31, 2016, pp. 211-217.

[5] Fan Tie-lin, Chen Mi-mi, Zhao Feng-qing The preparation of phase change energy storage ceramsite from waste autoclaved aerated concrete. Procedia Environmental Sciences, Vol. 31, 2016, pp. 227-231

[6] Metin Davraza, Murat Korub, Ali Ekrem Akdağ. The Effect of Physical Properties on Thermal Conductivity of Lightweight Aggregate Procedia Earth and Planetary Science, Vol. 15, 2015, pp. 85-92.

[7] Kartushina Yu. N., Shaikhiev I. G., Ananyev D. Waste treatment plants and charcoal production wastes as a corrective additive in the production of ceramsite. Vestnik of Kazan Technological University, Vol.17, Is.21, 2014, pp. 195-198.

[8] Sokolov L.I., Fomenko A.I. Reclamation of Waste Products in Aglite Production. Industry ecology. Vol. 19, 9, 2015, pp. 30-34.

[9] Kislenko T.A., Koshkarev S.A., Sidyakin P.A., Eremyan S.P. The Basic Significance Of Parameters Of Inertial Devices Cleaning Ventilation Emissions In Claydite Manufacturing. Modern problems of science and education, 1, 2014.

[10] Toropkov N.E. Influence of molding conditions clay matters for claydite and waste treatment methods of claydite production. Scientific Almanac, 8 (10), 2015, pp. 1039-1045. 
[11] Maksimova I.N., Makridin N.I. Technological Features Of Light Concretes Structure And Properties Formation. Regional architecture and engineering, 2, 2012, pp 45-48.

[12] Castrodale R.W., Harmon, K.S. Increasing Design Efficiency Using Lightweight Concrete for Prestressed Girder Bridges. Paper 55, Proceedings, 2005 National Bridge Conference, Palm Springs, CA, PCI, October 16-19, 2005.

[13] Castrodale R.W., Eriksson R.L., Barngrover B. Comparative Bridge Designs Using Normal Weight and Lightweight Concrete. Paper 45, Proceedings, 2009 National Bridge Conference, San Antonio, TX, PCI, September 13-15, 2009.

[14] Vaiana R., Capiluppi G.F., Gallelli V., Iuele T., Minani V. Pavement Surface Performances Evolution: an Experimental Application. Procedia - Social and Behavioral Sciences, Vol. 53, 3 October, 2012, pp. 1149-1160.

[15] Galitskov S.Ya., Galitskov K.S., Samohvalov O.V. Modelling Operating Area of Condition and Management of High Strength Bloating Clay, Stoving in a Rotary Kiln. Procedia Engineering, XXV R-S-P Seminar, Theoretical Foundation of Civil Engineering (25RSP), Vol. 111, 2016, pp. 233-235.

[16] Galitskov S.Ja., Galitskov K.S., Samohvalov O.V., Fadeev A.S. Modeling the calcination of ceramsite in a rotary furnace with regulated speed as a control object. Science Review, 7, 2015, pp. 227-237.

[17] Galitskov S. Y., Samokhvalov O. V., Fadeev A. S. Structural synthesis of a multi-dimensional system for automated control of claydite baking in a rotary furnace. Science Review, 12, 2013, pp. 204-208.

[18] Galitskov K.S., Samohvalov O.V. Strength properties of expanded clay and their reflection in the range of various temperature modes of three supporting cross-sections of kiln. Promyshlennoe i grazhdanskoe stroitelstvo [Industrial and Civil Engineering], 9, 2015, pp. 91-94.

[19] Vorobyov V.A., Ilyukhin A.V., Kolbasin O.M., Popov V.P. Automating preparation of concrete mixtures and manufacturing of reinforced-concrete products and structures. Publishing House of the Russian Academy of engineering, 2016, 660 p.

[20] Vorobyov V.A., Ilyukhin A.V., Kolbasin O.M., Popov V.P. Automating the production of concrete mixtures for road construction. Publishing House of the Russian Academy of engineering, 2014, $420 \mathrm{p}$

[21] Rapoport, E.Ya., Pleshivtseva Yu.E. Optimal control of thermal management of induction heating. Moscow, Science, 2012, 309 p. 